\title{
BMJ Open Patient-centredness as a quality domain in Swedish healthcare: results from the first national surveys in different Swedish healthcare settings
}

\author{
Ketevan Kandelaki, ${ }^{1}$ Gaetano Marrone, ${ }^{1}$ Cecilia Stålsby Lundborg, ${ }^{1}$ \\ Ingrid Schmidt, ${ }^{2}$ Ingeborg Björkman ${ }^{1,3}$
}

To cite: Kandelaki $\mathrm{K}$ Marrone G, Lundborg CS, et al. Patient-centredness as a quality domain in Swedish healthcare: results from the first national surveys in different Swedish healthcare settings. BMJ Open 2016;6: e009056. doi:10.1136/ bmjopen-2015-009056

- Prepublication history and additional material is available. To view please visit the journal (http://dx.doi.org/ 10.1136/bmjopen-2015009056).

Received 11 June 2015 Revised 19 November 2015 Accepted 2 December 2015

\section{CrossMark}

${ }^{1}$ Department of Public Health Sciences, Health Systems and Policy (HSP), Karolinska Institutet, Stockholm,

Sweden

${ }^{2}$ The Swedish National Board of Health and Welfare,

Stockholm, Sweden

${ }^{3}$ Department of Public Health and Caring Sciences, Health Services Research, Uppsala University, Uppsala, Sweden

Correspondence to Dr Ketevan Kandelaki; ketokandelaki@yahoo.com

\section{ABSTRACT}

Objectives: Patients' perception of the quality and patient-centredness of healthcare has gained increasing interest in the last decade in Sweden, as in other countries. The purpose of the study was to evaluate to what extent patients perceived Swedish healthcare as patient-centred and to explore the satisfaction levels related to gender, education level and to having or not having Swedish as one's mother tongue.

Design and settings: This study has a crosssectional design. Analyses were based on the first national patient surveys in Sweden, conducted between 2009 and 2010. The surveys included responses from 232518 patients who had been in contact with primary, outpatient, inpatient, or emergency care units. Survey questions related to indicators of patientcentred care and sociodemographic variables were selected for the analysis. The patients' level of satisfaction in the selected indicators was analysed and compared by sociodemographic and background factors. Multivariable logistic regression models were used for analysis.

Results: The patients expressed high levels of satisfaction in questions related to the 'Respect' indicator (81-96\% satisfied) but lower levels in most of the other indicators of patient-centred care. Only $25-30 \%$ of the patients reported they had been told about possible warning signs of their condition or treatment and 58-66\% said they had received enough information about their condition. Group differences were detected. The most satisfied patient groups were men, individuals with low levels of education and those with Swedish as their mother tongue.

Conclusions: According to these first national patient surveys, achieving patient-centred healthcare for all citizens is a challenge for Swedish healthcare authorities. Future analyses of national patient surveys should show whether national efforts to encourage acceptance of patient-centred approaches and strategies for equal care will give intended results.

\section{BACKGROUND}

In 2004, the WHO highlighted patientcentred care as part of their patient safety

\section{Strengths and limitations of this study}

- Strengths of our study are that it covers four different types of healthcare settings, with many units in each setting, and that the participants include patients from most parts of Sweden.

- All respondents had had a recent experience of a healthcare visit, and we were able to check for self-reported health status in the analysis.

- The number of respondents is large enough to give a comprehensive picture of central aspects of patient-centredness in the Swedish healthcare system.

- One of our aims was to estimate differences in perceptions related to gender, socioeconomic factors and having or not having Swedish as one's mother tongue. However, it is likely that we underestimated the disparities among these groups, due to the comparatively lower response rates among them.

- Another limitation is the questionnaire design, which gives important information at a population level, but on the other hand fails to give deeper understanding of people's perceptions and thoughts.

programme. ${ }^{1}$ In 2008, under the title 'Putting people first', the organisation emphasised that, in order to achieve overall targets for primary healthcare, the patient's perspective must be the focus of all measures taken. ${ }^{2}$ The issue of the patient's perspectives remains vitally important; research demonstrates that a patient-centred approach has favourable effects on a number of outcomes. ${ }^{3-5}$

\section{What is patient-centred care?}

The origin of the term 'patient-centred care' is usually attributed to various similar terms that were introduced in the 1950s and 1960s. In contrast to 'disease-centred medicine', researchers and practitioners started to use expressions such as 'patient-centred 
medicine', 'person-centred medicine' or 'client-centred counselling, ${ }^{6}$ hoping that the new terminology would move the focus away from diseases to a more holistic perspective where a patient is viewed as a whole person. ${ }^{7}$

\section{Measurements of patient-centred care in Sweden}

In 2005, the Swedish National Board of Health and Welfare defined patient-centred care as "care given with respect and consideration for the specific needs, expectations and values of the individual, and that these are taken into account in clinical decisions'. 8 An additional, elaborated definition was presented in $2008 .{ }^{9}$

Patient-centred care was included as one of the quality domains in the framework of 'Good care', developed by The Swedish National Board of Health and Welfare in $2006{ }^{8}$ The other domains were safety, accessibility, efficiency and equity. The domains were originally defined by the Institute of Medicine in the USA in $2001 .^{10}$ The quality domains were operationalised by The Swedish National Board of Health and Welfare into indicators and associated questions to enable measurement of patients' perceptions of the quality of care. ${ }^{11}$ The questions were constructed to measure different aspects of healthcare from patients' perspectives. ${ }^{11}$ This work was based on experiences from Picker Institute, UK, ${ }^{12}$ and the questionnaires can be understood as Swedish versions of the UK questionnaires. A study supported the internal validity of the inpatient hospital care survey. ${ }^{13}$ National patient surveys on patient-centredness have been conducted in the UK since 2001. ${ }^{14}$

Parts of the results of this first Swedish national patient survey have been presented previously, primarily in Swedish reports. However, no overview from four different settings, including reports of the attitudes among subgroups, has been brought out into the international public domain. The aim of this study was to explore to what extent patients in different healthcare settings in Sweden perceived healthcare as patient-centred and to capture the various demographic factors affecting these perceptions.

\section{METHODS}

The focus of this study is patients' perceptions of patient-centredness in Swedish healthcare. Analyses were based on the first national patient surveys in Sweden, including cross-sectional data from 2009 and 2010. The surveys were conducted by a survey institute (Indicator) on behalf of the Swedish Association of Local Authorities and Regions (SALAR). Survey data were shared with the research group. The present study was made on behalf of the National Board of Health and Welfare, which has the right to use data from the national patient surveys together with SALAR. Thus ethical approval was not required. The members of the research group were not involved in the development of the survey questionnaires (see online supplementary file) and did not conduct the data collection.

\section{Data collection}

The first national patient survey in Sweden was launched in 2009 and addressed patients in primary care. In subsequent years, surveys were conducted in outpatient, inpatient and emergency care settings (table 1). Swedish healthcare is organised into 21 regions and county councils, and most of them participated in the surveys.

The surveys were conducted by a survey institute (Indicator); it describes the data collection as follows: all patients who visited the selected healthcare unit during four consecutive weeks of the study period were registered. Patient information files were sent to the survey institute, which had the mandate to manage the survey. From these files, random samples of patients were taken. In the primary and outpatient care surveys, samples were based on a standard random sample of 200 patients per unit, which was later adjusted to the number of visitors at each setting. This procedure was also applied in the inpatient care survey, however, the breaking point here was 100 patients. In the emergency care survey, a random sample of 400 patients per unit was used. The techniques listed above were used due to the variation in numbers of patients visiting different types of healthcare settings.

The SALAR was involved in the development of the questionnaires (see online supplementary file). The core questions in the questionnaires were based on the Picker survey. Minor justifications and additions were conducted, which were later user-tested and piloted, but only on a small scale.

The selected patients each received a postal survey questionnaire (see online supplementary file) and a return envelope within 1-4 weeks after their visits to the healthcare units. Reminders were sent twice, after 2 and 4 weeks. The second reminder contained another copy

Table 1 Information on the four national patient surveys

\begin{tabular}{lllll}
\hline Setting & Year & Numbers of units & Number of respondents & Response rate \% \\
\hline Primary care* $^{*}$ & 2009 & 830 centres & 94662 & 59.7 \\
Outpatient care $†^{\text {Inpatient hospital care }}$ & 2010 & 967 outpatient clinics & 88268 & 63.7 \\
Emergency care $^{*}$ & 2010 & 727 inpatient clinics & 34603 & 66.5 \\
& 2010 & 89 emergency care units & 14985 & 53.7
\end{tabular}

${ }^{*}$ All counties and regions participated except Norrbotten and Stockholm.

†All counties and regions participated except Kronoberg, Norrbotten and Stockholm.

$\ddagger$ All counties and regions participated except Kronoberg, Norrbotten, Västerbotten and Stockholm. 
of the questionnaire. It was also possible to respond to the questionnaire online, in Swedish or in several other languages. Questionnaires where at least one question was answered were included in the analyses. Individuals who visited the unit more than once during the study period were included only once.

The surveys consisted of items addressing different aspects of healthcare from the patients' perspective (selected items, table 2). Patients were asked to judge whether they were fully, partially, or not at all satisfied with each item. The current study analysed items regarding the patient-centredness and captured the disparities related to gender, age, education level and having or not having Swedish as one's mother tongue.

\section{Data analysis}

Questions related to patient-centred care were selected for the analysis (table 2). The selection of questions, judged to be reflecting each indicator, was performed by two of the authors (IS and IB). For instance, in the primary care survey, five questions were included to measure the indicator 'Respect' (the patient is treated respectfully as an individual). These five questions were: (1) Did you feel that you were treated considerately and respectfully?, (2) How were you treated by the person with whom you made the appointment?, (3) How do you assess the way you were treated at the clinic reception?, (4) How do you assess the doctor's approach? and (5) How do you assess the way you were treated by the laboratory personnel?. Of these five, two were selected to the present analysis (questions 1 and 4). In the second analysis (logistic regression), one question was selected for each indicator. Here, a core question or a question judged to be the most important was chosen. In the example presented above, question 1 was selected for the logistic regression analysis. Similar selections were chosen for the analysis of the other indicators.

The analysis also examined associations between level of satisfaction and some possible explanatory variables: age (continuous); gender (man/woman); Swedish as mother tongue (yes/no); years of education $(\leq 9 / \leq 12 />12)$.

The association between each outcome and explanatory variables was studied using logistic regression models. In the regression models, each outcome was dichotomised as 'completely satisfied' versus 'otherwise' (ie, when patients answered that they were partially satisfied, not satisfied or 'not applicable'). ORs of not being completely satisfied versus being completely satisfied were calculated, and $\mathrm{p}$ values $<0.05$ were considered statistically significant.

$\mathrm{OR}>1$ have to be read as an indication of odds for not being satisfied regarding the selected question for the group considered, compared with the reference group. The final results were adjusted by region, number of previous contacts with healthcare units during the past 6 months and perception of one's own health status.
RESULTS

The total number of respondents was 232518. The response rate in the four settings varied between $54 \%$ and $67 \%$. In all four settings, the response rates were lower among younger people and among men. The webbased questionnaire was used by $5.4-7.3 \%$ of the respondents, and $0.3-0.4 \%$ used a language other than Swedish.

The background characteristics of the patients who answered the surveys are summarised in table 3 . There were more female participants in all four surveys. The majority of patients $(>90 \%)$ had Swedish as their mother tongue. In terms of education status, around $40 \%$ had 9 years or less of education, followed by $30-35 \%$ having up to 12 years.

Table 4 presents the level of patients' satisfaction. The highest level of satisfaction $(81-89 \%)$ was found in the 'Respect' indicator, and $92-96 \%$ of patients were satisfied with how they had been addressed by their physicians. A high grade of satisfaction was also seen in the 'Experiences addressed' indicator, where $84-90 \%$ of the patients reported they were satisfied with how they had been listened to by the physician. On the contrary, another question related to the same indicator rendered among the lowest levels of satisfaction. Only 36-37\% answered that their doctor had questioned them about any previous illnesses or health problems. Two questions with the lowest levels of satisfaction were those concerning whether the doctor had told them about possible warning signs ('Possible warning signs' indicator) (25$30 \%$ satisfied) and the question of whether they had joined in and discussed referrals on planning and implementation of the patient's own care ('Feels involved' indicator), with $21-42 \%$ satisfied.

\section{Regression analysis}

Six questions, one in each of the six indicators, were used in regression analyses (see the questions and indicators in table 4). The details of regression analysis are presented in table 5 .

From all types of healthcare settings, women expressed lower satisfaction levels than men in all indicators except 'Feels involved'; no difference compared with men was noted in the 'Feels involved' indicator in the emergency care survey.

In primary care, patients not having Swedish as their mother tongue had lower satisfaction levels in three indicators ('Respect', 'Patient's experience addressed' and 'Feels involved'). Regarding inpatient hospital care, a lower satisfaction level was reported in only one indicator among patients not having Swedish as their mother tongue ('Feels involved'). Patients with more than 9 years of education were less satisfied in most of the indicators in all four surveys. Results were adjusted by region, number of previous contacts with healthcare units during the past 6 months and perception of one's own health status. 
Table 2 The six defined indicators of patient-centred care for Good care concept and questions constructed to measure the level of patient-centred care in Sweden

\begin{tabular}{|c|c|}
\hline Indicator & Explanation \\
\hline $\begin{array}{l}\text { The patient is treated } \\
\text { respectfully as an } \\
\text { individual }\end{array}$ & $\begin{array}{l}\text { This is one of the basic requirements in } \\
\text { patient-centred healthcare. All care should } \\
\text { be based on respect of all people's } \\
\text { equality, the dignity of the individual and the } \\
\text { individual's autonomy and integrity. } \\
\text { Respectful treatment should characterise } \\
\text { everything from the first encounter } \\
\text { throughout the whole care process } \\
\text { HSL (1982:763) } \S 2 a\end{array}$ \\
\hline $\begin{array}{l}\text { The patient's own } \\
\text { knowledge and } \\
\text { experiences are } \\
\text { utilised }\end{array}$ & $\begin{array}{l}\text { It is important that the patient is met } \\
\text { according to his/her social circumstances } \\
\text { and that the care is given with respect and } \\
\text { sensitivity for the individual's specific } \\
\text { needs, conditions, expectations and values } \\
\text { By utilising the patient's own knowledge } \\
\text { and experiences, the chances of being able } \\
\text { to participate in his or her own health, care } \\
\text { and treatment are increased }\end{array}$ \\
\hline
\end{tabular}

The patient is offered Health and medical services are obliged to individualised information concerning state of health, diagnosis and methods for examinations, care and treatment

The patient receives sufficient information and support to handle his or her own health*

The patient is offered the possibility of desired continuity of healthcare contacts*

Involvement in the planning and implementation of the patient's own care $^{\star}$ Questions in the surveys selected for analysis

Study variables

Did you feel that you were treated

Respect

considerately and respectfully?

How do you assess the doctor's approach? give the patient individualised information concerning state of health, diagnosis and methods for examinations, care and treatment. This is regulated in HSL (1982:763) § 2a) and in LYHS (Professional Activities in the Health and Medical Field Act) (1998:531), chapter $2 \S 2$. Through information, the patient can gain the knowledge, understanding and insight that are needed for involvement. If the information cannot be given to the patient it should instead be offered to the relatives The information provided should give the patient knowledge, understanding and insight, offer prerequisites for the patient's involvement and have an impact on his or her own health, care and treatment

The greatest possible continuity of contacts and information should be sought and different measures should be coordinated in a useful way to strengthen the possibility of independence in daily life. This indicator is supported in HSL (1982:763) § 2a

The healthcare should be based on the individual's autonomy and integrity. The care and treatment should as far as

Did the doctor take sufficient regard of your own skills and experiences of your illness/your problem?

Did the doctor listen to what you had to say?

Do you believe that the doctors took a holistic approach to your care? (inpatient hospital care)

Did the doctor enquire about any previous illnesses or health problems that you felt were relevant to the visit?

Did you get enough information about your condition?

When you asked the doctor about something that was important to you, did you get an answer that you understood?

Did the doctor tell you about the possible warning signs that you should be aware of regarding your condition or treatment?

Did the doctor explain what you should do if problems or symptoms were to continue, worsen or return?

Did you know where you could go if you needed help or had any further questions after the visit?

Did you feel involved in decisions about your care and treatment to the extent that you wanted? possible be planned and implemented in agreement with the patient. This is regulated in HSL (1982:763) § 2a. Patients' involvement has an impact on adherence to and outcome of the treatment
Did you join in the discussion of referrals for continuing care with other healthcare providers or hospitals? Did you feel that you were involved in the planning of your continued healthcare?

r

Feels

Patient's experience addressed

Enough information

Possible warning signs

Continuity of care involved

Table translated by the authors, from the National Swedish Board of Health and Welfare's original.

${ }^{*}$ Comment in the National Indicators of Good care report: ${ }^{11}$ "The questions in the National Health Survey must probably be further developed to cover this indicator".

HSL, Health and Medical Services Act; LYHS, Professional Activities in the Health and Medical Field Act. 
Table 3 Background characteristics of patients answering the surveys conducted in primary care, outpatient hospital care, inpatient hospital care and emergency care

\begin{tabular}{|c|c|c|c|c|}
\hline Characteristics & $\begin{array}{l}\text { Primary care } \\
\%(n) \\
\mathrm{N}=94662\end{array}$ & $\begin{array}{l}\text { Outpatient hospital } \\
\text { care \% (n) } \\
\mathrm{N}=\mathbf{8 8 2 6 8}\end{array}$ & $\begin{array}{l}\text { Inpatient hospital } \\
\text { care } \%(n) \\
N=34603\end{array}$ & $\begin{array}{l}\text { Emergency } \\
\text { care } \%(n) \\
\mathrm{N}=14985\end{array}$ \\
\hline \multicolumn{5}{|l|}{ Sex } \\
\hline Male & 38.5 (34 705) & $42.9(35900)$ & $46.3(15321)$ & 45.4 (6622) \\
\hline Female & $61.5(55462)$ & 57.1 (47 863) & 53.7 (17 803) & $54.6(7960)$ \\
\hline \multicolumn{5}{|l|}{ Age (years) } \\
\hline $16-44$ & $29.0(26771)$ & $21.9(19011)$ & $13.2(4466)$ & $26.3(3790)$ \\
\hline $45-64$ & $30.9(28543)$ & 31.5 (27 351) & 26.4 (8956) & 29.7 (4278) \\
\hline $65-74$ & $19.8(18319)$ & $25.3(21909)$ & $25.6(8691)$ & $20.2(2917)$ \\
\hline$\geq 75$ & $20.2(18691)$ & $21.3(18472)$ & $34.7(11776)$ & $23.8(3435)$ \\
\hline \multicolumn{5}{|c|}{ Education (in years) } \\
\hline$\leq 9$ & 40.5 (36 037) & 38.4 (32 315) & $48.2(16$ 110) & $39.5(5644)$ \\
\hline$\leq 12$ & 36.3 (32 276) & $35.8(30143)$ & $32.3(10786)$ & $37.2(5316)$ \\
\hline$>12$ & $23.2(20586)$ & $25.8(21670)$ & $19.5(6512)$ & 23.2 (3315) \\
\hline \multicolumn{5}{|l|}{ Mother tongue } \\
\hline Swedish & 90.7 (84 574) & 92.4 (80 322) & $92.2(31306)$ & $90.2(13108)$ \\
\hline Not Swedish & $9.3(8657)$ & $7.6(6631)$ & $8.0(2738)$ & $9.8(1423)$ \\
\hline \multicolumn{5}{|c|}{ Number of previous contacts with healthcare units the past 6 months } \\
\hline Never & $15.6(14481)$ & $11.5(9988)$ & $20.2(6797)$ & $25.5(3682)$ \\
\hline Once & $19.6(18254)$ & $16.3(14$ 103) & $16.1(5413)$ & $18.1(2620)$ \\
\hline 2-3 times & $36.5(33946)$ & $32.9(28467)$ & $30.7(10333)$ & $29.4(4250)$ \\
\hline$\geq 4$ times & $28.3(26330)$ & $39.3(34024)$ & $33.0(11$ 127) & 26.9 (3889) \\
\hline \multicolumn{5}{|c|}{ Perception of one's own heath } \\
\hline Excellent & $9.9(9187)$ & $10.6(9171)$ & $8.6(2927)$ & $13.2(1914)$ \\
\hline Very good & 22.5 (20 973) & $21.8(18$ 870) & 18.3 (6191) & 23.0 (3327) \\
\hline Good & 33.0 (30 709) & $32.0(27721)$ & 28.9 (9789) & 29.1 (4216) \\
\hline Ok & 28.1 (26 142) & 28.6 (24 772) & $34.0(11515)$ & 26.7 (3867) \\
\hline Bad & $6.5(6069)$ & $7.0(6085)$ & $10.1(3428)$ & 7.9 (1143) \\
\hline
\end{tabular}

Analyses on the 'age' variable showed that older age correlated to higher levels of patients' satisfaction (not presented in table 5).

\section{DISCUSSION}

This study explored a number of different aspects related to patient-centredness as perceived by patients in Swedish healthcare. The findings of the first national patient surveys in Sweden highlight a number of areas for improvement. In addition, the study revealed some significant disparities between groups, related to variables including gender and not having Swedish as one's mother tongue.

The national patient survey indicated that many patients in Sweden were satisfied in one out of the six studied indicators of patient-centred care, namely 'Respect'. However, for all other indicators, a large proportion of patients were not satisfied. For instance, less than two-thirds (58-66\%) reported that they had received enough information about their conditions and less than one-third (25-30\%) had received enough information about possible warning signs of which they were to be aware. Furthermore, only $58-69 \%$ felt involved in decision-making about their treatment and 16-42\% reported that they had been involved in the planning of their healthcare.
In general, patients gave similar scores regardless of which healthcare unit they had visited, but a few disparities were noted. Patients from inpatient care were more satisfied with how they had been involved in the care planning and also knew where to seek further help in case of necessity. More patients in outpatient care were satisfied $(78 \%)$ compared with patients in emergency care $(65 \%)$ with how the doctor addressed the questions that were important to them.

The results from the present study with low levels of satisfaction in patient-centred issues are consistent with findings from The Swedish Agency for Health and Care Services Analysis. ${ }^{15}$ Sweden was also low in comparison with other countries. In five of the six studied dimensions of patient-centredness, Sweden showed lower satisfaction than the UK, Switzerland, the USA, New Zealand, Australia, Canada, the Netherlands, Germany, France and Norway. ${ }^{15}$

\section{Differences among groups of patients}

Our findings suggest that having a foreign background, having higher education, or being a woman, were associated with lower satisfaction levels. Similar results have been reported in other studies. One study suggested that inpatient healthcare primarily satisfied independent patients in good health, ${ }^{13}$ and another found that the 
Table 4 Indicators related to patient-centeredness analysed in four healthcare settings in Sweden

\begin{tabular}{|c|c|c|c|c|c|}
\hline Questions (indicators) & Options & $\begin{array}{l}\text { Primary } \\
\text { care } \%(n)\end{array}$ & $\begin{array}{l}\text { Outpatient } \\
\text { hospital } \\
\text { care } \% \text { (n) }\end{array}$ & $\begin{array}{l}\text { Inpatient } \\
\text { hospital } \\
\text { care \% (n) }\end{array}$ & $\begin{array}{l}\text { Emergency } \\
\text { care \% (n) }\end{array}$ \\
\hline Did you feel that you were treated considerately & Yes & $81.9(76215)$ & $88.7(76$ 680) & $84.5(28569)$ & $80.6(11629)$ \\
\hline and respectfully?* (Respect) & Otherwise & $18.1(16823)$ & $11.3(9735)$ & $15.5(5246)$ & $19.4(2806)$ \\
\hline How do you assess the doctor's approach? & Good & 91.7 (85 929) & 95.5 (83 355) & 92.5 (31 337) & $92.1(12434)$ \\
\hline (Respect) & Otherwise & $8.3(7763)$ & $4.5(3924)$ & $7.5(2554)$ & $7.9(1071)$ \\
\hline Did the doctor take sufficient regard of your own & Yes & $65.5(61220)$ & $72.5(62577)$ & - & - \\
\hline $\begin{array}{l}\text { skills and experiences of your illness/problem?* } \\
\text { (Experiences addressed) }\end{array}$ & Otherwise & 34.1 (32 192) & $27.4(23686)$ & - & - \\
\hline Did the doctor listen to what you had to say? & Yes & 83.5 (78 344) & $89.9(77608)$ & - & - \\
\hline (Experiences addressed) & Otherwise & $16.5(15472)$ & $10.1(8678)$ & - & - \\
\hline Do you believe that the doctors took a holistic & Yes & - & - & $62.3(20206)$ & - \\
\hline approach to your care? (Experiences addressed) & Otherwise & - & - & $37.7(12215)$ & - \\
\hline Did the doctor enquire about any previous & Yes & 35.9 (33 438) & $37.0(31890)$ & - & - \\
\hline $\begin{array}{l}\text { illnesses or health problems that you felt were } \\
\text { relevant to the visit? (Experiences addressed) }\end{array}$ & Otherwise & $64.1(59763)$ & $63.0(54353)$ & - & - \\
\hline Did you get enough information about your & Yes & $57.6(53460)$ & $66.3(57012)$ & $64.0(21572)$ & $60.8(8756)$ \\
\hline condition $?^{\star}$ (Enough information) & Otherwise & $42.4(39386)$ & $33.8(29002)$ & $36.0(12135)$ & 39.3 (5652) \\
\hline When you asked the doctor about something that & Yes & $73.1(68365)$ & 77.7 (67 355) & $67.6(22856)$ & $64.9(8812)$ \\
\hline $\begin{array}{l}\text { was important to you, did you get an answer that } \\
\text { you understood? (Enough information) }\end{array}$ & Otherwise & $26.9(25204)$ & $22.3(19348)$ & $32.4(10970)$ & $35.0(4758)$ \\
\hline Did the doctor tell you about the possible warning & Yes & $24.6(22862)$ & $29.0(24728)$ & $30.3(10062)$ & $27.8(2297)$ \\
\hline $\begin{array}{l}\text { signs that you should be aware of regarding your } \\
\text { condition or treatment?* }{ }^{*} \text { (Possible warning signs) }\end{array}$ & Otherwise & $75.4(70197)$ & $71.0(60583)$ & $69.8(23193)$ & $72.3(5978)$ \\
\hline Did the doctor explain what you should do if & Yes & $47.2(43976)$ & $44.9(38383)$ & $44.9(15098)$ & - \\
\hline $\begin{array}{l}\text { problems or symptoms were to continue, worsen } \\
\text { or come back? (Possible warning signs) }\end{array}$ & Otherwise & $52.8(49202)$ & $55.0(47038)$ & $55.1(18493)$ & - \\
\hline Did you know where you could go if you needed & Yes & $47.6(44153)$ & $60.0(50588)$ & $70.3(23590)$ & $57.5(4764)$ \\
\hline $\begin{array}{l}\text { help or had any further questions after the visit?* } \\
\text { (Continuity of care) }\end{array}$ & Otherwise & $52.4(48536)$ & $40.0(33727)$ & $29.6(9961)$ & $42.5(3523)$ \\
\hline Did you feel involved in decisions about your care & Yes & $63.2(58342)$ & $69.1(58$ 297) & $62.4(20714)$ & $58.5(8304)$ \\
\hline $\begin{array}{l}\text { and treatment to the extent that you wanted?* } \\
\text { (Feels involved) }\end{array}$ & Otherwise & $36.8(33921)$ & $30.9(26076)$ & $37.6(12484)$ & $41.5(5879)$ \\
\hline Did you join in the discussion of referrals for & Yes & $21.2(19726)$ & $16.2(13502)$ & $42.4(13990)$ & - \\
\hline $\begin{array}{l}\text { continuing care with other healthcare providers or } \\
\text { hospitals? Did you feel that you were involved in } \\
\text { the planning of your continued healthcare? (Feels } \\
\text { involved) }\end{array}$ & Otherwise & 78.7 (73 222) & $83.8(69987)$ & $57.6(19000)$ & - \\
\hline
\end{tabular}

most satisfied groups were older, with excellent health status and with lower levels of education. ${ }^{16}$ In a UK survey, ${ }^{14}$ better experiences of healthcare were correlated with being older, male and White. In the present study, we controlled for self-reported health status. Patients with foreign backgrounds rated higher satisfaction levels in some of the indicators of patient-centred care. However, low satisfaction levels were commonly demonstrated in the 'Respect', 'Patient's experience addressed' and 'Feels involved' indicators. It is known that people with foreign backgrounds experience poorer quality of healthcare. In the UK, non-White patients reported negative experiences, especially concerning access and waiting times, involvement in decisions about their care and treatment, and regarding the quality of information given to them. ${ }^{14}$ In the Netherlands, patients of non-Dutch ethnic origins described inadequate information exchange with care providers, and experience of prejudiced behaviour on the part of care providers. ${ }^{17}$ In Australia, persons from five different non-English speaking areas discussed significant barriers and the need for greater access to interpreters, and culturally appropriate communication and education. ${ }^{18}$ An earlier study from Sweden identified complex and intertwined challenges, including sociocultural diversity, the language barrier and challenges that migrants face in navigating through the Swedish healthcare system. ${ }^{19}$

\section{National patient surveys and impact on quality of care}

A large number of surveys aimed at patients and residents have been carried out on the international level. ${ }^{11}$ Whether national patient surveys have impact on the quality of healthcare is not clear, and only a few scientific papers focusing on this issue could be found. 
Table 5 Logistic regression models for primary care, outpatient hospital care, inpatient hospital care and emergency care

\begin{tabular}{|c|c|c|c|c|c|c|}
\hline Indicators & $\begin{array}{l}\text { Respect, OR } \\
(95 \% \mathrm{Cl})\end{array}$ & $\begin{array}{l}\text { Patient's experience } \\
\text { addressed, OR }(95 \% \mathrm{Cl})\end{array}$ & $\begin{array}{l}\text { Enough information, OR } \\
(95 \% \mathrm{Cl})\end{array}$ & $\begin{array}{l}\text { Possible warning signs, } \\
\text { OR }(95 \% \mathrm{Cl})\end{array}$ & $\begin{array}{l}\text { Continuity of care, } \\
\text { OR }(95 \% \mathrm{Cl})\end{array}$ & $\begin{array}{l}\text { Feels involved, } \\
\text { OR }(95 \% \mathrm{Cl})\end{array}$ \\
\hline Primary care & $(n=93038)$ & $(n=93692)$ & $(n=92846)$ & $(n=93059)$ & $(n=92689)$ & $(n=92263)$ \\
\hline \multicolumn{7}{|l|}{ Gender } \\
\hline Men & Ref & Ref & Ref & Ref & Ref & Ref \\
\hline Women & $1.154(1.110 \text { to } 1.201)^{*}$ & $1.043(1.013 \text { to } 1.073)^{*}$ & $1.117(1.084 \text { to } 1.150)^{*}$ & $1.206(1.167 \text { to } 1.247)^{*}$ & $1.128(1.096 \text { to } 1.161)^{*}$ & $0.914(0.887 \text { to } 0.943)^{*}$ \\
\hline \multicolumn{7}{|l|}{ Language } \\
\hline Swedish & Ref & Ref & Ref & Ref & Ref & Ref \\
\hline Other & $1.261(1.189 \text { to } 1.337)^{*}$ & $1.517(1.440 \text { to } 1.598)^{*}$ & 1.021 (0.971 to 1.073$)$ & $0.655(0.621 \text { to } 0.691)^{\star}$ & $0.790(0.753 \text { to } 0.830)^{*}$ & $1.561(1.484 \text { to } 1.641)^{*}$ \\
\hline \multicolumn{7}{|c|}{ Education (in years) } \\
\hline$\leq 9$ & Ref & Ref & Ref & Ref & Ref & Ref \\
\hline$\leq 12$ & $1.046(1.000$ to 1.095$)$ & $0.896(0.866 \text { to } 0.928)^{*}$ & $1.209(1.168 \text { to } 1.252)^{*}$ & $1.083(1.041 \text { to } 1.126)^{*}$ & $1.056(1.021 \text { to } 1.093)^{\star}$ & $1.004(0.968$ to 1.040$)$ \\
\hline$>12$ & $0.955(0.906$ to 1.007$)$ & $0.766(0.737 \text { to } 0.797)^{\star}$ & $1.239(1.191 \text { to } 1.289)^{\star}$ & $1.160(1.110 \text { to } 1.213)^{\star}$ & $1.144(1.101 \text { to } 1.189)^{*}$ & $0.907(0.870 \text { to } 0.945)^{\star}$ \\
\hline Outpatient care & $(n=76264)$ & $(n=77452)$ & $(n=75991)$ & $(n=75447)$ & $(n=74554)$ & $(n=75054)$ \\
\hline \multicolumn{7}{|l|}{ Gender } \\
\hline Men & Ref & Ref & Ref & Ref & Ref & Ref \\
\hline Women & $1.215(1.155 \text { to } 1.279)^{*}$ & $1.063(1.021 \text { to } 1.106)^{*}$ & $1.146(1.106 \text { to } 1.188)^{*}$ & $1.093(1.053 \text { to } 1.133)^{*}$ & $1.125(1.075 \text { to } 1.177)^{*}$ & $0.905(0.876 \text { to } 0.935)^{\star}$ \\
\hline \multicolumn{7}{|l|}{ Language } \\
\hline Swedish & Ref & Ref & Ref & Ref & Ref & Ref \\
\hline Other & $1.329(1.228 \text { to } 1.438)^{*}$ & $1.359(1.272 \text { to } 1.452)^{*}$ & $1.145(1.076 \text { to } 1.218)^{*}$ & $0.803(0.754 \text { to } 0.856)^{\star}$ & $1.071(0.993$ to 1.156$)$ & $1.499(1.416 \text { to } 1.586)^{*}$ \\
\hline \multicolumn{7}{|c|}{ Education (in years) } \\
\hline$\leq 9$ & Ref & Ref & Ref & Ref & Ref & Ref \\
\hline$\leq 12$ & $1.050(0.988$ to 1.115$)$ & $1.050(1.001 \text { to } 1.102)^{*}$ & $1.215(1.164 \text { to } 1.268)^{*}$ & $1.131(1.082 \text { to } 1.181)^{*}$ & $1.102(1.044 \text { to } 1.164)^{*}$ & $1.026(0.987$ to 1.066$)$ \\
\hline$>12$ & $0.982(0.918$ to 1.050$)$ & 0.988 (0.937 to 1.042$)$ & $1.324(1.263 \text { to } 1.388)^{*}$ & $1.212(1.154 \text { to } 1.273)^{*}$ & $1.229(1.158 \text { to } 1.305)^{*}$ & $0.927(0.888 \text { to } 0.968)^{*}$ \\
\hline Inpatient care & $(n=31925$ & No data available & $(n=32130)$ & $(n=30575)$ & $(n=31334)$ & $(n=31495)$ \\
\hline \multicolumn{2}{|l|}{ Gender } & - & & - & & \\
\hline Men & Ref & - & Ref & - & Ref & Ref \\
\hline Women & $1.360(1.271 \text { to } 1.455)^{*}$ & - & $1.172(1.113 \text { to } 1.233)^{*}$ & $1.316(1.252 \text { to } 1.383)^{*}$ & $1.288(1.220 \text { to } 1.359)^{*}$ & $1.012(0.963$ to 1.064$)$ \\
\hline \multicolumn{2}{|l|}{ Language } & - & & - & & \\
\hline Swedish & Ref & - & Ref & - & Ref & Ref \\
\hline Other & $1.046(0.933$ to 1.173$)$ & - & $0.883(0.804 \text { to } 0.970)^{\star}$ & $0.637(0.584 \text { to } 0.696)^{\star}$ & $0.704(0.641 \text { to } 0.773)^{*}$ & $1.163(1.063 \text { to } 1.272)^{*}$ \\
\hline \multicolumn{2}{|l|}{$\begin{array}{l}\text { Education } \\
\text { (in years) }\end{array}$} & - & & - & & \\
\hline$\leq 9$ & Ref & - & Ref & - & Ref & Ref \\
\hline$\leq 12$ & $1.174(1.083 \text { to } 1.273)^{*}$ & - & $1.216(1.144 \text { to } 1.294)^{*}$ & 1.046 (0.988 to 1.107$)$ & $1.182(1.108 \text { to } 1.260)^{*}$ & $1.141(1.075 \text { to } 1.211)^{*}$ \\
\hline \multirow[t]{2}{*}{$>12$} & $1.341(1.223 \text { to } 1.471)^{*}$ & - & $1.396(1.299 \text { to } 1.501)^{*}$ & $1.244(1.161 \text { to } 1.333)^{*}$ & $1.420(1.314 \text { to } 1.534)^{*}$ & $1.148(1.069 \text { to } 1.232)^{*}$ \\
\hline & & - & & - & & \\
\hline Emergency care & $(n=14435)$ & No data available & $(n=14408)$ & $(n=8275)$ & $(n=8287)$ & $(n=14183)$ \\
\hline Gender & & - & & & & \\
\hline Men & Ref & - & Ref & Ref & Ref & Ref \\
\hline Women & $1.431(1.307 \text { to } 1.567)^{*}$ & - & $1.297(1.204 \text { to } 1.397)^{*}$ & $1.224(1.095 \text { to } 1.367)^{*}$ & $1.126(1.027 \text { to } 1.235)^{*}$ & $1.035(0.963$ to 1.112$)$ \\
\hline
\end{tabular}




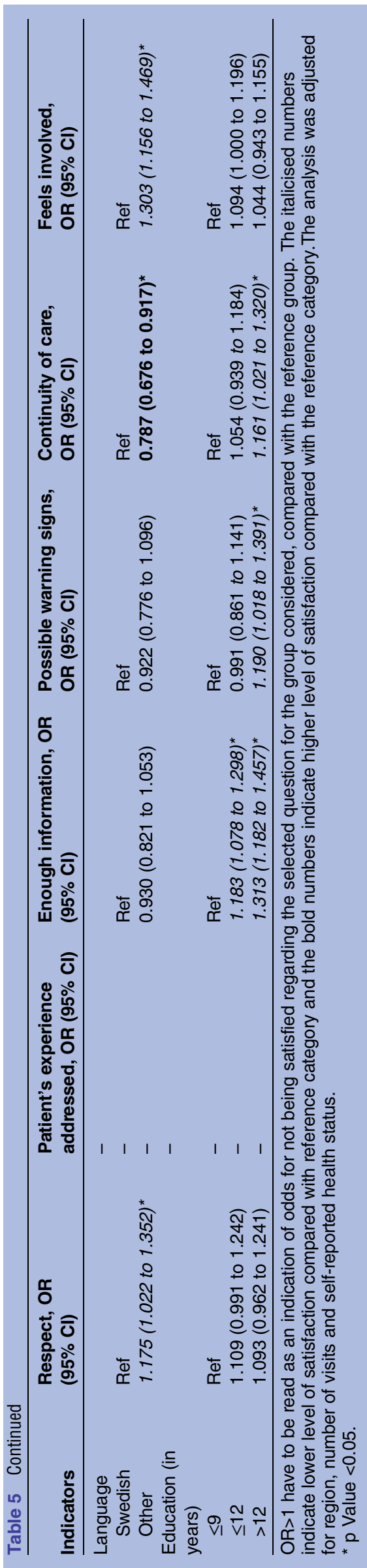

When national patient surveys were introduced in the UK in 2001, the intention was to provide a method to 'enable the health service to measure itself against aspirations and experience of its users, to compare performance across the country, and to analyse trends over time'. ${ }^{14}$ Furthermore, expectations were that the surveys would help services to become more patient-centred. It is possible that the authorities in Sweden had similar expectations when the Swedish surveys were launched. However, when the researchers studied the effect of the yearly UK surveys from 2002 to 2009, they concluded that there was very little improvement in patients' experience of healthcare. ${ }^{14}$ Barriers for health professionals' and managers' use of patient survey data to improve patient-centred care were described as organisational, professional and data related. ${ }^{20}$

Whether surveys in Sweden will have the desired impact on the level of patient-centredness in Swedish healthcare is difficult to predict. A number of strategies to increase the patient-centredness in healthcare have been launched by the Swedish government. For example, a campaign commissioned by the Ministry of Social Affairs focused on vulnerable elderly patients and promoted patient-centredness. ${ }^{21}$ In 2015 a new patient law was launched, with the aim of further strengthening the position of the patient in healthcare. ${ }^{22}$

A national strategy for the years 2012-2016, launched by the Swedish government, addresses methods aiming at increasing equality in healthcare. ${ }^{23}$ Active work towards equality requires awareness and knowledge of the existing differences in health among different groups. The national strategy for equality in healthcare contains, among a number of other approaches, the visualisation and analysis of disparities in care, treatment and treatment results. ${ }^{23}$ This study is an example of how disparities among groups of patients can be illuminated. Developing patient-centred care is essential in order to improve healthcare quality. The objective is to recognise that needs of every patient must be met and treated individually.

Equality in health and healthcare can be reached by a patient-centred approach where all persons receive care and treatment based on their individual needs. ${ }^{23}$ Factors related to patient-centredness are related to the overall rating of care. ${ }^{14} 16$ Many actors involved in Swedish healthcare are implementing efforts with the aim to reinforce more patient-centred care. The role of the national patient surveys in this process is to continue measuring and to follow the development of Swedish patients' perceptions of healthcare quality, including the degree of patient-centredness.

\section{Methodological considerations}

The analysis was adjusted for self-reported health status as less favourable experiences are commonly reported by patients with poorer self-rated health status. ${ }^{13}$ Also, the number of previous healthcare visits were adjusted for in the analyses. Poorer self-rated health status has 
been demonstrated among Swedish Assyrian/ Syrian-born patients in comparison with that of Sweden-born patients. ${ }^{24}$ The study was also adjusted for geographic areas, because regional differences in the quality of healthcare have been demonstrated. ${ }^{23}$

It is possible that many patients with foreign backgrounds were less likely to participate in this survey. This group seemed to be under-represented as the participants reporting not having Swedish as their mother tongue constituted between $7.6 \%$ and $9.8 \%$ of the total responders. Population statistics from 2009 also show that $14.3 \%$ of Swedish citizens were born outside Sweden, and when Swedish-born citizens with both parents born outside Sweden were included, this group represented $18.6 \%$ of the total population. ${ }^{25}$

The number of patients included from the four different healthcare settings was high. The response rate was $54 \%$ to $66 \%$. This level of response rate is common in citizen surveys conducted by local healthcare authorities and regions.

It is important to note that, despite the high number of study participants, we cannot exclude the possibility that less satisfied patients did not participate in the survey. An important question is whether the non-responders have different experiences than those who responded. A study based on a patient survey in Denmark explored possible bias due to non-respondents. ${ }^{26}$ There, the total response rate was $54 \%$. Background characteristics were compared and the conclusion was that the difference between respondents and non-respondents was minor. However, in a small subgroup, such as the patients with foreign backgrounds in the present study, it is possible that this selection of patients caused a more pronounced bias of the results. If this is the case, the results probably have a positive bias and, consequently, the presented disparities are not exaggerated.

Despite the fact that later surveys have been conducted, we still consider it valuable to present the results of the first surveys, as they provide a baseline for potential future analysis.

\section{CONCLUSIONS}

In conclusion, the first national patient surveys in Sweden revealed that patients were mainly satisfied with one aspect of patient-centredness, that is, 'Respect', whereas large proportions of patients were not satisfied with the other analysed aspects ('Patient's experience addressed', 'Enough information', 'Possible warning signs', 'Continuity of care' and 'Feels involved'). Many patients felt that they were met with respect and were satisfied with how they had been treated by the doctor. Fewer were satisfied with the information about their condition and possible warning signs, and also with how they had been involved in the planning of care.

Differences in experiences of patient-centredness existed among patient groups. Lower levels of satisfaction were registered among women, persons not having
Swedish as their mother tongue and persons with higher levels of education.

Ongoing national programmes in Sweden promote increased patient-centredness in healthcare, and emphasise this approach as a strategy for equal care. Analyses of future national patient surveys should show whether these efforts will give the intended results.

Contributors KK made substantial contributions to the concept development and study design, and actively participated in statistical data analyses and interpretation of results. She drafted the first version of the manuscript and revised it based on input from the coauthors. GM was involved in the study design. He contributed to the statistical data analyses and general supervision of the research project. CSL contributed to the concept and design, gave intellectual input and provided constructive comments, suggestions and coordination. IS initiated the study and influenced the overall concept and design. She participated in the literature review and health system analyses, and made major contributions to drafting of the manuscript and revising it critically. IB made substantial contributions to the manuscript's final version.

She participated in concept design and was involved in drafting the manuscript and revising it critically for important intellectual content.

Funding The Swedish national patient surveys are funded by the local authorities and regions responsible for Swedish healthcare, in cooperation with SALAR (Swedish Association of Local Authorities and Regions). The analysis included in this study and the manuscript preparation were funded by The Swedish National Board of Health and Welfare.

Competing interests None declared.

Provenance and peer review Not commissioned; externally peer reviewed.

Data sharing statement No additional data are available.

Open Access This is an Open Access article distributed in accordance with the Creative Commons Attribution Non Commercial (CC BY-NC 4.0) license, which permits others to distribute, remix, adapt, build upon this work noncommercially, and license their derivative works on different terms, provided the original work is properly cited and the use is non-commercial. See: http:// creativecommons.org/licenses/by-nc/4.0/

\section{REFERENCES}

1. WHO. Patients for Patient Safety-Statement of Case. How patient engagement became a priority. http://www.who.int/patientsafety/ patients_for_patient/statement/en/

2. WHO. The World Health Report 2008. Primary health care-now more than ever. Geneva: WHO, 2008.

3. Vermeire E, Hearnshaw $\mathrm{H}$, Van Royen $\mathrm{P}$, et al. Patient adherence to treatment: three decades of research. A comprehensive review. $J$ Clin Pharm Ther 2001;26:331-42.

4. Greenfield S, Kaplan SH, Ware JE Jr, et al. Patients' participation in medical care: effects on blood sugar control and quality of life in diabetes. J Gen Intern Med 1988;3:448-57.

5. Sidani S. Effects of patient-centered care on patient outcomes: an evaluation. Res Theory Nurs Pract 2008;22:24-37.

6. Balint M. Treatment or diagnosis: a study of repeat prescriptions in general practice. London, New York: Tavistock Publications in association with Methuen, 1984.

7. Balint E. The possibilities of patient-centered medicine. J R Coll Gen Pract 1969;17:269-76.

8. The National Board of Health and Welfare. God vård-om ledningssystem för kvalitet och patientsäkerhet $i$ hälso- och sjukvården. [Good care-on management systems for quality and patient safety in health care]. Stockholm: The national Board of Health and Welfare of Sweden/ Socialstyrelsen, 2006.

9. The National Board of Health and Welfare. Nationellaindikatorerförgod vård-diskussionsunderlag. [National indicators for good care-a basis for discussion]. Stockholm, 2008

10. Institute of Medicine (IoM US) Committee on Quality of Health Care in America. "Crossing the Quality Chasm: A New Health System for the 21st Century" Washington (DC): National Academies Press (US); 2001. 
11. The National Board of Health and Welfare. Health care report 2009. Stockholm, 2010.

12. Coulter A, Cleary PD. Patients' experiences with hospital care in five countries. Health Affairs 2001;20:244-52.

13. Wolf $A$, Olsson LE, Taft $C$, et al. Impacts of patient characteristics on hospital care experience in 34,000 Swedish patients. BMC Nurs 2012;11:8.

14. DeCourcy A, West E, Barron D. The National Adult Inpatient Survey conducted in the English National Health Service from 2002 to 2009: how have the data been used and what do we know as a result? BMC Health Serv Res 2012;12:71.

15. Docteur E, Coulter A. Patient-centeredness in Sweden's health system. Vårdanalys: The Swedish Agency for Health and Care Services Analysis, 2012. http://vardanalys.se/Global/Rapporter\% 20pdf-filer/2013/2012-7-Patientcenteredness-v7\%200-web.pdf (accessed 2 Mar 2013).

16. Rahmqvist M, Bara AC. Patient characteristics and quality dimensions related to patient satisfaction. Int J Qual Health Care 2010;22:86-92.

17. Suurmond J, Uiters $\mathrm{E}$, de Bruijne MC, et al. Negative health care experiences of immigrant patients: a qualitative study. BMC Health Serv Res 2011;11:10.

18. Komaric N, Bedford S, van Driel ML. Two sides of the coin: patient and provider perceptions of health care delivery to patients from culturally and linguistically diverse backgrounds. BMC Health Serv Res 2012;12:322.
19. Nkulu Kalengayi FK, Hurtig AK, Ahlm C, et al. "It is a challenge to do it the right way": an interpretive description of caregivers' experiences in caring for migrant patients in Northern Sweden. BMC Health Serv Res 2012;12:433.

20. Davies E, Cleary PD. Hearing the patient's voice? Factors affecting the use of patient survey data in quality improvement. Qual Saf Health Care 2005;14:428-32.

21. The Swedish Association of Local Authorities and Regions (SALAR). Bättre liv för sjuka äldre [Better life for the frail elderly]. 2014. http:// www.skl.se/socialomsorgstod/aldre/battrelivforsjukaaldre/bakgrund. 1718.html

22. The Swedish Government. Delbetänkande för Patientlag (SOU 2013:2). [Interim Report on Patient Law (SOU 2013:2)]. 2013.

23. The National Board of Health and Welfare. Ojämna villkor för hälsa och vård-Jämlikhetsperspektiv på hälso- och sjukvården. [Unequal conditions for health and health care-equality perspectives in health care]. 2011.

24. Taloyan M, Wajngot A, Johansson SE, et al. Poor self-rated health in adult patients with type 2 diabetes in the town of Södertalje: a cross-sectional study. Scand J Prim Health Care 2010;28: 216-20.

25. Statistics Sweden. Population statistics. 2013. http://www.scb.se/ Pages/TableAndChart 26041.aspx (accessed Mar 2013).

26. Rosenstjerne Andersen A, Fuglsang M, Kyed D. The National Danish Survey of Patient Experiences has a small positive bias. Ugeskr Laeger 2012;174:2372-4. 